\title{
ASYMPTOTIC EXPANSIONS OF THE LOGARITHM OF THE GAMMA FUNCTION IN THE TERMS OF THE POLYGAMMA FUNCTIONS
}

\author{
CHAO-PING CHEN
}

Abstract. We present new asymptotic expansions of the logarithm of the gamma function in terms of the polygamma functions. Based on these expansions, we prove new complete monotonicity properties of some functions involving the gamma and polygamma functions. As consequences of them we establish new upper and lower bounds for the gamma function in terms of the polygamma functions.

Mathematics subject classification (2010): Primary 33B15; secondary 41A60, 26 A48.

Keywords and phrases: Gamma function, digamma function, polygamma functions, complete monotonicity, asymptotic expansion, inequality.

\section{REFERENCES}

[1] M. Abramowitz And I. A. Stegun (Editors), Handbook of Mathematical Functions with Formulas, Graphs, and Mathematical Tables, Applied Mathematics Series 55, Ninth printing, National Bureau of Standards, Washington, D.C., 1972.

[2] J. Dubourdieu, Sur un théorème de M. S. Bernstein relatif à la transformation de Laplace-Stieltjes, Compositio Math. 7 (1939), 96-111 (in French).

[3] H. van Haeringen, Completely monotonic and related functions, J. Math. Anal. Appl. 204 (1996), 389-408.

[4] H. ŞEVLI AND N. BATIR, Complete monotonicity results for some functions involving the gamma and polygamma functions, Math. Comput. Modelling 53 (2011), 1771-1775.

[5] H. M. SRivastaVA, J. ChOI, Series associated with the zeta and related functions, Kluwer Academic Publishers, Dordrecht, Boston and London, 2001.

[6] H. M. SRivastava And J. ChOI, Zeta and q-Zeta functions and fssociated feries and integrals, Elsevier Science Publishers, Amsterdam, London and New York, 2012.

[7] D. V. WIDDER, The Laplace Transform, Princeton Univ. Press, Princeton, 1941. 